\title{
HISTOLOGICAL VARIANCES OF MORINGA OLIFERA ON THE KIDNEY OF ADULT WISTAR RATS
}

\author{
ADETUNJI OPEYEMI ADEBOLA ${ }^{1,2 *}$, OYEWO OLUWATOYIN ${ }^{2}$, ADETUNJI IYABODE TOYIN $^{3}$, NWOBI NNENA LINDA ${ }^{4}$
}

${ }^{1}$ Department of Anatomy, School of Basic Medical Sciences, Benjamin S. Carson (SNR.) College of Medicine, Babcock University, Ilisan-Remo, Ogun State, Nigeria. ${ }^{2}$ Department of Anatomy, Faculty of Basic Medical Sciences, College of Medicine, Ladoke Akintola

University of Technology, Ogbomoso, Oyo State, Nigeria. ${ }^{3}$ Department of Pure and Applied Biology, Ladoke Akintola University of Technology, Ogbomoso, Oyo State, Nigeria. ${ }^{4}$ Department of Chemical Pathology, School of Pre-Clinical Sciences, Babcock University, Ogun State, Nigeria. Email: adetunjiop@babcock.edu.ng

Received: 18 February 2021, Revised and Accepted: 18 March 2021

\section{ABSTRACT}

Aim and Objectives: Demonstrating the exact quantity of Moringa oleifera (MO) that will cure any hepatocyte diseases and the one that can harm the hepatocytes of the Adult Wistar rats.

Methods: Twenty (20) adult Wistar rats (both sex) were used for the study (caged based on same sex to avoid mating and pregnancy) and were randomly assigned into four groups ( $\mathrm{n}=5$ ); A-Control, B-250 mg/body weight (BW) of MO, C-500 mg/BW of MO, and D-750 mg/BW of MO orally.

Result: The crude aqueous extract of MO Lam, shows insignificant increased in BW at the $1^{\text {st }}$ week of administration which latter dropped little by little doing the weeks of the administration in groups $(\mathrm{B}, \mathrm{C}$, and $\mathrm{D})$ rats, by comparing $(\mathrm{p}<0.05)$ to the control group after MO administration, the organ (Kidneys) shows a significant difference between the kidneys (left and right kidneys) in relation to the control group rats. MO increases the weight of the animals morphologically by comparing the weight of the animals before and after administration. Histological sections shows a normal Glomerulli, Peri-Glomerular Space, Convoluted Tubules, and Interstitium, after administration of the Crude Aqueous Extract of Mo lame in terms with the control group rats.

Conclusion: MO is a good herb that has no damage effect on the body and hepatocytes but of more beneficial.

Keywords: Crude aqueous extract, Moringa oleifera leaves, Hepatocytes.

(C) 2021 The Authors. Published by Innovare Academic Sciences Pvt Ltd. This is an open access article under the CC BY license (http://creativecommons. org/licenses/by/4.0/) DOI: http://dx.doi.org/10.22159/ijms.2021v9i3.41144. Journal homepage: https://innovareacademics.in/journals/index.php/ijms

\section{INTRODUCTION}

Herbal toxicity has been reported on some herbs used for curing of different ailment, one of the occurrences of toxicity involving Chinese herbs between 1991 and 1992 in Belgium, in which young woman were admitted to hospitals due to renal failure [1]. The moringa tree is native to the southern foothills of the Himalayas, Africa, and the Middle East. The root contains an active anti-biotic principle, pterygospermin. The root bark contains two alkaloids, namely, moringine and moringinine [2]. India ancient traditional medicine called it Ayurveda says the leaves of the Moringa tree prevent 300 diseases. Modern science is confirmed that these leaves could help prevent untold suffering and death caused by malnutrition and related diseases [2,3]. Study had shown that Moringa oleifera (MO) have various ability to cure different disease, in which diabetes is not an exception [4].

The kidneys been a dark-red, bean-shaped organs in, one side of the kidney bulges convex and the other side is concave. There is a cavity attached to the concave side of the kidney, called the Renal Pelvis, which extends into the ureter. Kidney is enclosed in the renal capsule, which helps to protect them against infections and trauma. It is divided into two main areas, a light outer area called the renal cortex, and a darker inner area called the renal medulla. The renal artery delivers blood to the kidneys each day. Over $180 \mathrm{l}$ (50 gallons) of blood pass through the kidneys every day. When this blood enters the kidneys, it is filtered and returned to the heart through the renal vein [5]

Pharmaceutical drugs are designed to elicit specific reactions. Their associated side effects are undesired actions, usually traded as a "risk" against the "benefit" of the primary effect. Herbs trend to have several broad actions on a number of whole physiological systems. These actions are usually oriented in the same general therapeutic direction and are usually complementary or synergistic, often non-specific, and very rarely adverse. Herb actions cannot be adequately described using the vocabulary of "drug," for exapme, diuretic they are too complex. The clearest example of this is the coining of the term "adaptogenic" used to describe the multiple non-specific effects of herbs such as Ginseng [6].

\section{METHODS}

The ethical committee of the Ladoke Akintola University of Technology, Ogbomoso, approved the commencement of the research (LAUTRC: 10345). Twenty (20) adult Wistar rats ([both sex] were caged based on same sex to avoid mating and pregnancy) with average weight of $110 \mathrm{~g}$ were randomly assigned into four groups; $A, B, C$, and $D$ of $(n=5)$ in each group. Animal in Group A served as control while animals in group B, $\mathrm{C}$, and $\mathrm{D}$ serve as treated groups at different dosage $(\mathrm{B}=250 \mathrm{mg} / \mathrm{body}$ weight [BW], $\mathrm{C}=500 \mathrm{mg} / \mathrm{BW}$, and $\mathrm{D}=750 \mathrm{mg} / \mathrm{BW}$ ) of the extract of $\mathrm{MO}$ orally. The rats were obtained and maintained in the Animal Holding of the Faculty of Basic Medical Science, Ladoke Akintola University of Technology, Ogbomoso, Oyo State, Nigeria. The animals were fed with grower's mash obtained from Bovajah Nig. Enterprises in Oke-Ado Area Ogbomoso, Oyo State, Nigeria.

Freshly plucked MO leaves were collected from moringa tree around Tippa garage area, Tanke, Ilorin, Kwara State, Nigeria, and were taken to the Botany section in the Pure and Apply Biology Department, Ladoke Akintola University of Technology, Ogbomoso for verification, identification, and authentication; and were latter dried at a room temperature $\left(25^{\circ} \mathrm{C}\right)$ and grounded to powder, which was then taken to Laboratory of Food Science, Ladoke Akintola University of Technology, Ogbomoso for Crude aqueous Extraction and was then moved to the 
site of the experimentation. Extraction process as carried out using the method described elsewhere [7-9].

The whole experiment lasted for 3 weeks (21 days) after which the animals were fasted overnight and were sacrificed by cervical

Table 1: Mean weight of the animals in each groups data

\begin{tabular}{lcc}
\hline Groups & Mean \pm S.E.M & p-value \\
\hline A & $161.67 \pm 3.663$ & 0.0000 \\
A-B & $174.87 \pm 4.935$ & 0.0982 \\
A-C & $184.17 \pm 10.64$ & 0.1162 \\
A-D & $182.50 \pm 10.00$ & 0.1221 \\
B-C & $184.17 \pm 10.64$ & 0.4722 \\
B-D & $182.50 \pm 10.00$ & 0.5312 \\
C-D & $182.50 \pm 10.00$ & 0.9146 \\
\hline
\end{tabular}

At $5 \%$ level of significance, the data suggest that the mean weight of the rats does not differ significantly from each other

Table 2: Mean weight of the organ (Kidney) data

\begin{tabular}{lcc}
\hline Groups & Mean \pm S.E.M & p-value \\
\hline A & $0.5875 \pm 0.042500$ & 0.0000 \\
A-B & $0.5988 \pm 0.006250$ & 0.8179 \\
A-C & $0.5413 \pm 0.003750$ & 0.3916 \\
A-D & $0.5138 \pm 0.018750$ & 0.2533 \\
\hline
\end{tabular}

Since p-value $(0.00)<0.05$, at $5 \%$ level of significance, it is concluded that there is a significant difference between the left and right kidney after sacrificed
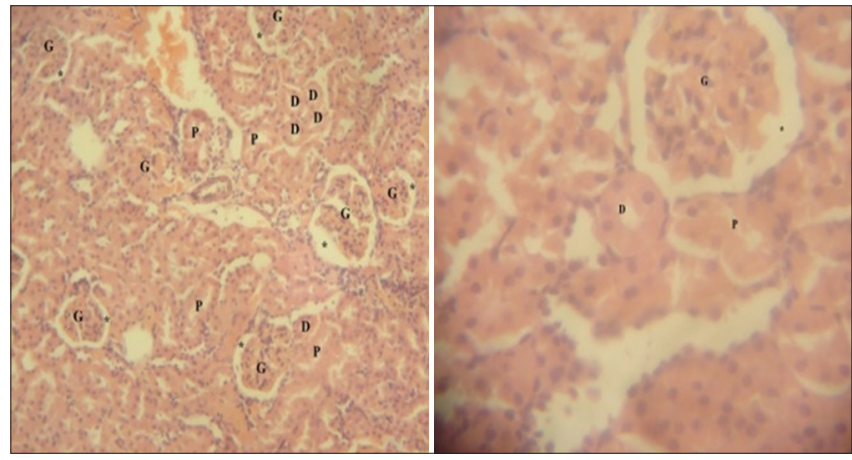

Fig. 1: Group A control rats photomicrograph of a kidney section showing normal Histology of glomeruli (G), distal (D) and proximal $(P)$ convoluted tubules, interstitium and periglomerular space $\left(^{*}\right)$. (Hematoxylin and Eosin Method $\times 100$ and $\times 400$, respectively)
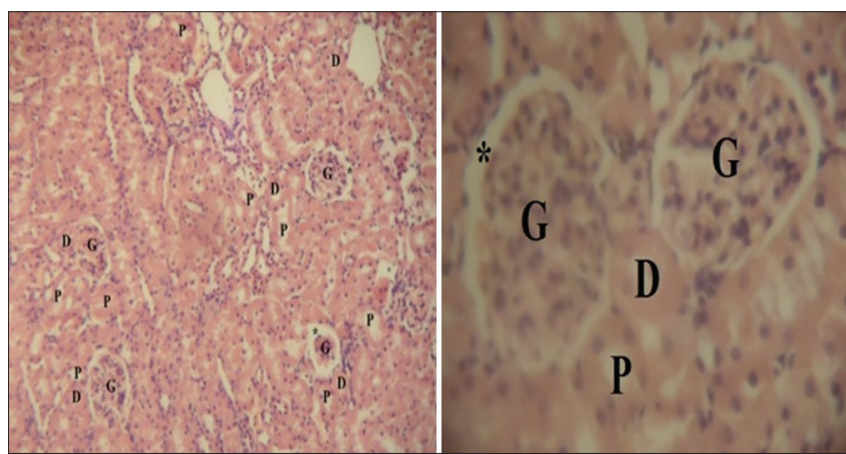

Fig. 2: Group B tested rats section of a kidney revealing normal histology of glomeruli (G), distal (D) and proximal (P) convoluted tubules, and glomerular Space $\left(^{*}\right)$. (Hematoxylin and Eosin Stain $\times 100$ and $\times 400$, respectively) dislocation and both kidney (Right and Left) were harvested and processed with Hematoxylin and Eosin using Drury, 1967 method, that reveal the histo-architectural effect of leaves extract of MO.

\section{RESULTS}

Data were presented as Means \pm SEM (standard error of mean). P value $(p<0.05)$ was considered statistically significant.

\section{DISCUSSION}

MO increases the weight of the animals morphologically by comparing the weight of the animals before administrating with after administration but at $5 \%$ level of significance; the data suggest that the mean weight (Table 1) of the rats does not differ significantly, likewise in between the left and right kidneys after sacrificing the rats. The rats in the treated group appeared active and well nourished, and the male treated group showed hyper-activeness in sexual acts in all groups except in control group.

The photomicrographs of the control Group A (Fig. 1) showed normal glomeruli, normal distal, and proximal convoluted tubules. These are keeping in line with normal kidney histological findings. The photomicrograph (Figs. 2-4) of the histology of the kidney of the treated groups (B, C, and D) also showed that normal glomeruli, distal, and proximal convoluted tubules are also within normal limit. There are similarities in the histological findings in these groups at different dosage and that of control analyzed. But when considering the weights of the animals, the bar charts show insignificant based on the P-value and the mean \pm S.E.M (Tables 1 and 2 ).
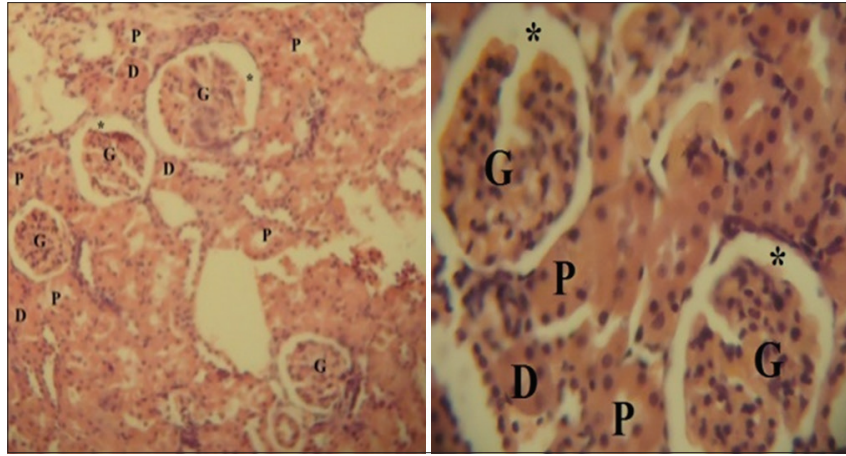

Fig. 3: Group C treated rats section of a kidney showing normal histology of glomeruli (G), distal (D) and proximal (P) convoluted tubules, and glomerular space $\left({ }^{*}\right)$. (Hematoxylin and Eosin method Stain of $\times 100$ and $\times 400$, respectively)
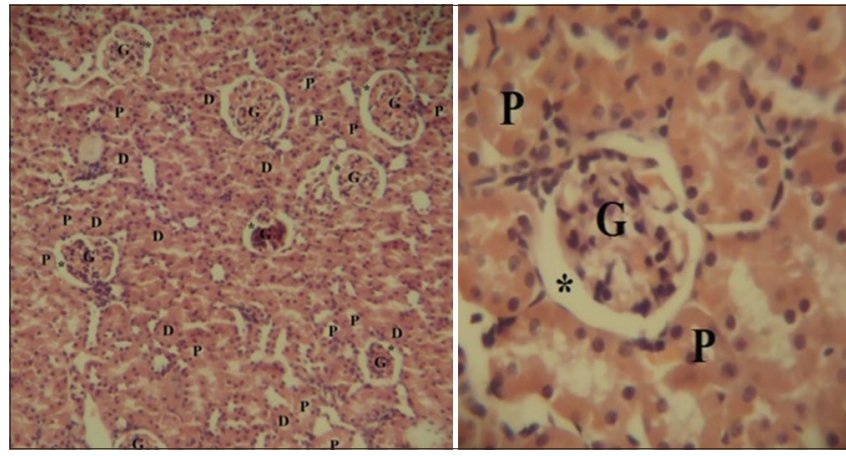

Fig. 4: Group D treated rats photomicrograph of a kidney section showing normal histology of glomeruli (G), distal (D) and proximal $(P)$ convoluted tubules, interstitium and periglomerular space $\left(^{*}\right)$. (Hematoxylin and Eosin method stain of $\times 100$ and $\times 400$, respectively) 


\section{CONCLUSION AND RECOMMENDATION}

MO is a good herb that has no damage effect to body and kidney but of more beneficial effect, the finding of this experiment indicates that both low and high dosage consumption of MO has more beneficial effect to body and kidney and it of no damage effect to body and kidney. Therefore, further studies are recommended to support the above findings. Serum, creatinine, and urea, electrolyte levels could be done for further elucidation of effects of the extracts on the kidney. Furthermore, creatinine and urea clearance could be done. The above are necessary before any conclusion could be made on the above findings because there might have been derangement of biochemical data before it could be noticed morphologically.

\section{REFERENCES}

1. Vanherweghem LJ. Misuse of herbal remedies: The case of an outbreak of terminal renal failure in Belgium (Chinese herbs nephropathy). J Altern Complement Med 1998;4:9-13

2. Paul CW, Didia BC. The effect of methanolic extract of Moringa oleifera lam roots on the histology of kidney and liver of guinea pigs. Asian J Med Sci 2012;4:55-60.

3. Fahey JW. Moringa oleifera: A review of the medical evidence for its nutritional, therapeutic, and prophylactic properties. Part 1. Trees Life J 2005; $1: 5-15$.

4. National Academy of Clinical Biochemistry Laboratory Medicine practice guidelines: Clinical utilization of cardiac biomarker testing in heart failure. Circulation 2007;116:e99-109.

5. Moore KL, Dalley AF, Agur AM. Clinical Oriented Anatomy. $5^{\text {th }}$ ed. Baltimore: Lippincott Williams and Wilkins; 2006.

6. Fabricant DS, Farnsworth NR. The value of plants used in traditional medicine for drug discovery. Environ Health Perspect 2001;109:69-75.

7. Harborne JB. Methods of plant analysis. In: Phytochemical Methods. Dordrecht: Springer; 1972. p. 1-32.

8. Uhegbu FO, Onwuchekwa CC, Iweala EE, Kanu I. Effect of processing methods on nutritive and antinutritive properties of seeds of Brachystegia eurycoma and Detarium microcarpum from Nigeria. Pak J Nutr 2005;8:316-20.

9. Nwinuka NM, Monanu MO, Nwiloh BI. Effects of aqueous extract of Mangifera indica L. (Mango) Stem bark on haematological parameters of normal albino rats. Pak J Nutr 2008;7:663-6. 